\title{
Role of cardiovascular magnetic resonance in pediatric pulmonary hypertension-novel concepts and imaging biomarkers
}

\author{
Heiner Latus, Christian Meierhofer \\ Clinic for Congenital Heart Disease and Pediatric Cardiology, German Heart Center Munich, Munich, Germany \\ Contributions: (I) Conception and design: All authors; (II) Administrative support: None; (III) Provision of study materials or patients: C Meierhofer; \\ (IV) Collection and assembly of data: All authors; (V) Data analysis and interpretation: All authors; (VI) Manuscript writing: All authors; (VII) Final \\ approval of manuscript: All authors. \\ Correspondence to: Heiner Latus, MD. Clinic for Congenital Heart Disease and Pediatric Cardiology, German Heart Center Munich, Technical \\ University Munich, Lazarettstr. 36, 80636 Munich, Germany. Email: heiner.latus@googlemail.com.
}

\begin{abstract}
Pulmonary hypertension $(\mathrm{PH})$ in children is a heterogenous disease of the small pulmonary arteries characterized by a progressive increase in pulmonary vascular resistance. Despite adequate medical therapy, long-term pressure overload is frequently associated with a progressive course leading to right ventricular failure and ultimately death. Invasive hemodynamic assessment by cardiac catheterization is crucial for initial diagnosis, risk stratification and therapeutic strategy. Although echocardiography remains the most important imaging modality for the assessment of right ventricular function and pulmonary hemodynamics, cardiovascular magnetic resonance (CMR) has emerged as a valuable non-invasive imaging technique that enables comprehensive evaluation of biventricular performance, blood flow, morphology and the myocardial tissue. In this review, we summarize the principles and applications of CMR in the evaluation of pediatric PH patients and present an update about novel CMR based concepts and imaging biomarkers that may provide further diagnostic, therapeutic and prognostic information.
\end{abstract}

Keywords: Pediatric pulmonary hypertension (pediatric PH); cardiovascular magnetic resonance imaging (CMR imaging); right ventricular dysfunction

Submitted Feb 29, 2020. Accepted for publication Apr 15, 2020.

doi: $10.21037 / \mathrm{cdt}-20-270$

View this article at: http://dx.doi.org/10.21037/cdt-20-270

\section{Introduction}

Advanced imaging plays an emerging role in the diagnosis and clinical follow-up of patients with pulmonary hypertension $(\mathrm{PH})(1,2)$. Although cardiovascular magnetic resonance (CMR) imaging becomes increasingly important in the evaluation of different types of $\mathrm{PH}$ (3), echocardiography still remains the first-line imaging technique if $\mathrm{PH}$ is suspected (4). Furthermore, invasive assessment by heart catheterization is required to confirm diagnosis and to evaluate pulmonary vasoreactivity to nitric oxide (NO) (5). Data derived from CMR, however, can provide valuable information both at initial diagnosis, for monitoring the response to $\mathrm{PH}$ targeted therapy and for risk stratification (3,6-11). Because CMR enables precise and reliable quantification of biventricular volumes, function and cardiac output, it is recommended as part of the routine clinical assessment of children with $\mathrm{PH}$ (12). In this review, we aim to provide practical information for the use of CMR in children and adolescents with PH. In view of recently published research in this area, we particularly thought to focus on novel CMR based concepts and developments that may be helpful in the evaluation of pediatric $\mathrm{PH}$ patients.

\section{Standard CMR parameters in children and adolescents with suspected PH}

The principles and applications of CMR for the evaluation of $\mathrm{PH}$ in children have been described in literature and include practical recommendations for its use in clinical 
routine (12). Examinations can be performed with 1.5 or 3.0 Tesla systems and standard equipment for performing a cardiac magnetic resonance (MR) examination must include cardiac coils, electrocardiogram (ECG) and respiratory monitoring, an appropriately equipped resuscitation cart and a CMR compatible infusion system. Gadolinium-based intravenous MR contrast agents are frequently administered in children for angiographic and tissue characterization studies. Overall, the incidence of adverse events in children is very low and reactions, if present, are mild in the majority of cases. However, the "off-label" use of contrast agent should be reconsidered in-depth on an individual basis and its advantages need to be weighed up against the potential risks $(3,13)$. In brief, the following components are frequently included in the CMR study protocol of a pediatric patient with suspected $\mathrm{PH}$ (see Table 1).

\section{Quantification of biventricular size and function by cine CMR}

Quantification of biventricular volumes and function represents the most important part of a CMR study in patients with $\mathrm{PH}$. Balanced steady state free precession (SSFP) cine sequences are typically applied that cover up the entire heart using a stack of short-axis or axial slices that provide 25-30 images per heartbeat. By measuring right (RV) and left ventricular (LV) volumes separately in both end-systole and end-diastole, stroke volume and ejection fraction $(\mathrm{EF})$ can be quantified $(3,12)$. CMR derived RV EF and LV stroke volume strongly correlate with survival in pediatric $\mathrm{PH}$ patients. In the largest CMR study including 100 children and adolescents with various types of $\mathrm{PH}$, an up to 2.6-fold increase in mortality was observed per decrease of these values by one standard deviation (9). van Wolferen et al. showed that RV measurements contain prognostic information in idiopathic pulmonary arterial hypertension (PAH) in adults: larger RV volumes, reduced RV stroke volume and smaller LV dimensions were independent predictors for mortality and therapy failure (35). Accordingly, since RV failure is the most common cause of mortality (36), cine CMR represents an ideal modality for follow-up monitoring $(7,35,37)$. Even in more complex forms of $\mathrm{PH}$, cine CMR derived impaired biventricular systolic function proved to be of prognostic importance as demonstrated in a cohort of adult patients with Eisenmenger syndrome (38).

\section{Phase contrast blood flow measurements}

Standard two-dimensional phase contrast velocity measurements allow accurate flow quantification in each vessel of interest $(12,39,40)$. Accordingly, calculation of cardiac output and shunt flow $(\mathrm{Qp} / \mathrm{Qs})$ both at baseline and during administration of pulmonary vasodilators is possible that may help to guide further therapy (21). Furthermore, right and left lung perfusion ratios, collateral flow and valvar regurgitation can be calculated. If considered necessary, pulmonary vein flows can be measured separately for each lung (41). Importantly, measurement of peak velocity by phase contrast to assess pressure gradients is less accurate with CMR and needs confirmation by Doppler echocardiography and cardiac catheterization.

\section{Morphological assessment}

In patients without any structural heart disease (PAH), the sustained increase in pulmonary artery pressure (PAP) leads to distension of the pulmonary artery system (Figures 1,2). The enlargement of these vessels in relation to the diameters of the ascending aorta is suggestive for the presence of PH $(15,42)$. Signs of increased intracavitary $\mathrm{RV}$ pressure may also be expressed by a flattened position of the interventricular septum with leftward shift in systole (see Figure 1) (43-45). Although typically ruled out by echocardiography, CMR helps to detect congenital heart disease (CHD) as the underlying cause for $\mathrm{PH}$ such as ventricular septal defect (Figures 2,3), a persistent arterial duct (Figure 4) and vascular abnormalities (anomalous pulmonary venous return, major aortopulmonary collateral arteries). Furthermore, other secondary causes such as pulmonary thromboembolism $(16,17)$, peripheral pulmonary artery stenosis or pulmonary venous obstruction can be detected using contrast-enhanced CMR angiography (7).

\section{Myocardial tissue characterization}

Myocardial tissue can be characterized using T1 and T2 weighted sequences, late gadolinium enhancement (LGE) and parametric myocardial mapping techniques. Thus, myocardial insult with edema, focal scarring and diffuse myocardial fibrosis may be visualized and quantified. While no study has yet assessed LGE in children with $\mathrm{PH}$, inconsistent data exists in the adult $\mathrm{PH}$ population 
Table 1 Summary of standard, optional and novel imaging parameters that can be assessed in a CMR examination of children with suspected PH

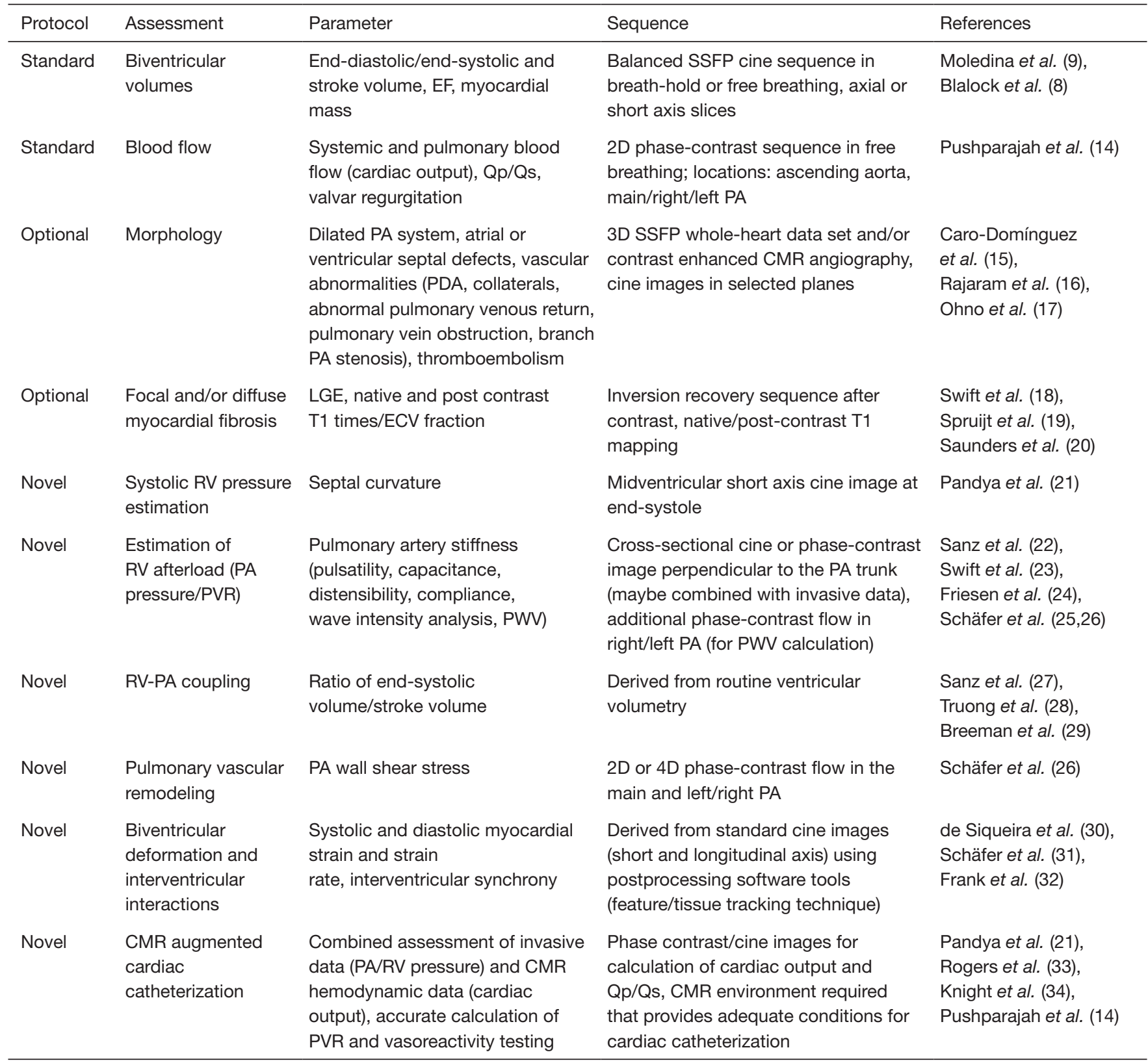

CMR, cardiovascular magnetic resonance; PH, pulmonary hypertension; EF, ejection fraction; SSFP, steady state free precession; PA, pulmonary artery; PDA, persistent arterial duct; LGE, late gadolinium enhancement; ECV, extracellular volume; RV, right ventricle; PVR, pulmonary vascular resistance; PWV, pulse wave velocity.

regarding the incidence and prognostic relevance of focal fibrosis (18,46-50). A study by Saunders et al. further showed that native T1 mapping may not be of additive value in the diagnostic or prognostic evaluation of patients with $\mathrm{PAH}$ although increased natives $\mathrm{T} 1$ times are frequently detected at the interventricular insertion points $(19,20)$. However, other studies evaluated the extracellular volume (ECV) fraction within the RV and LV and found diffuse $\mathrm{RV}$ fibrosis to correlate with RV functional parameters and global hemodynamics (51-53). 

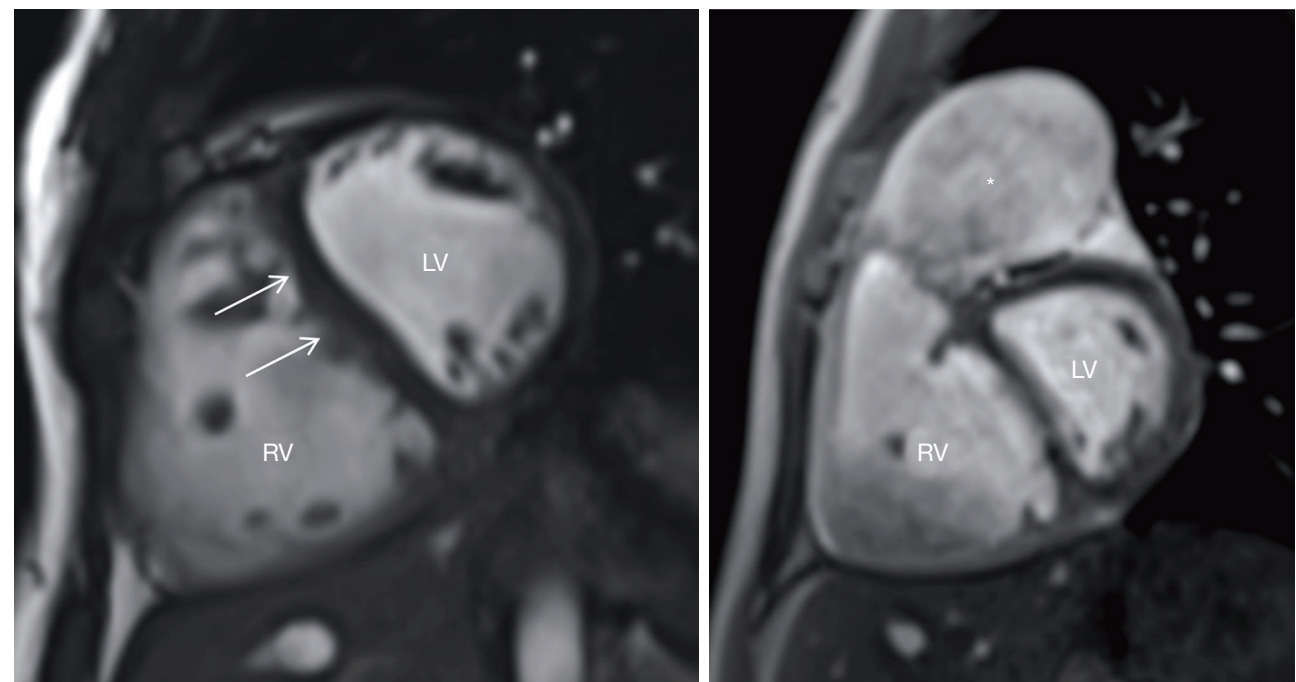

Figure $1 \mathrm{CMR}$ cine images of a 14-year-old female patient with idiopathic pulmonary arterial hypertension with systemic PA pressures. Left: short axis cine image showing RV hypertrophy and a leftward shift (arrows) of the interventricular septum ("septal flattening”) as a sign of elevated RV intracavitary pressure. Right: distension of the main pulmonary artery $\left(^{*}\right)$ as a result of increased pulmonary vascular resistance. $\mathrm{LV}$, left ventricular; $\mathrm{RV}$, right ventricular; CMR, cardiovascular magnetic resonance; PA, pulmonary artery.
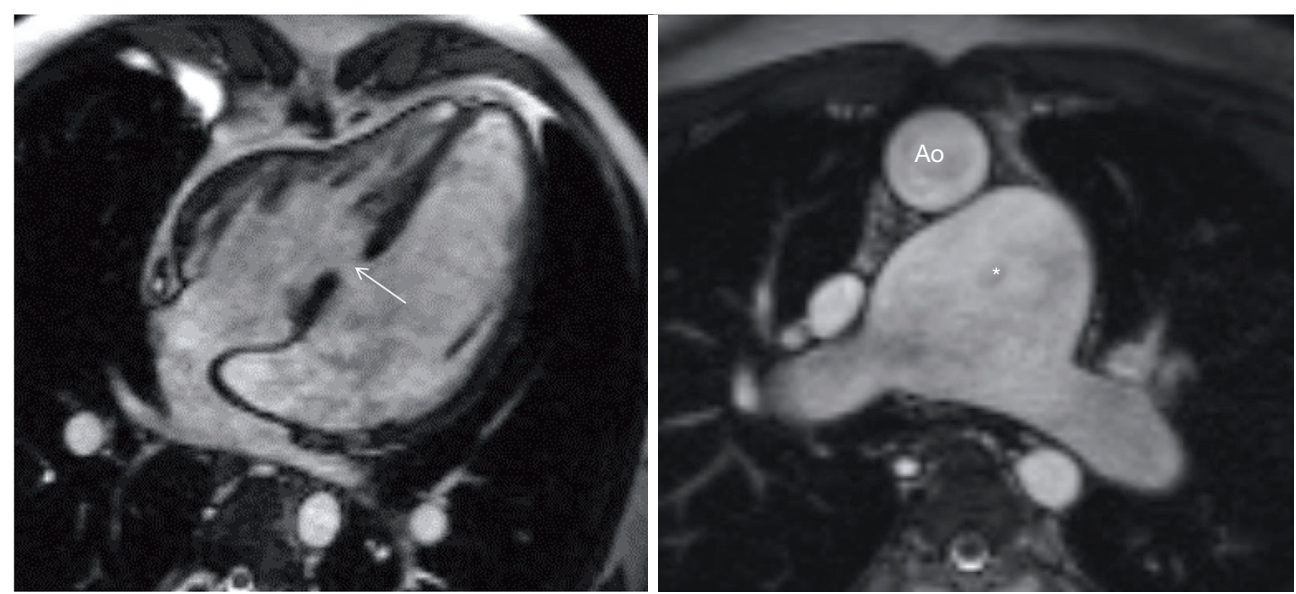

Figure 2 A 35-year-old patient with a secondary PH due to complex CHD (D-TGA after atrial switch, ventricular septal defect (arrow) and multiple aortopulmonary collaterals). Note the increase in pulmonary artery size ${ }^{*}$ ) compared to the ascending aorta (Ao). PH, pulmonary hypertension; CHD, congenital heart disease; D-TGA, dextro-transposition of the great arteries.

\section{Novel concepts and imaging biomarkers in pediatric PH using CMR}

Novel concepts and CMR derived imaging biomarkers become increasingly important in pediatric patients with PH. Ideally, such parameters should enable comprehensive assessment of both myocardial and pulmonary vascular remodeling and provide additional prognostic information. In recent years, several groups aimed to investigate $\mathrm{PH}$ hemodynamics by applying sophisticated CMR imaging techniques (see Table 1).

\section{Non-invasive estimation of $R V$ afterload and pulmonary vascular stiffness}

Estimation of RV afterload parameters using non-invasive CMR imaging techniques helps to establish diagnosis of 

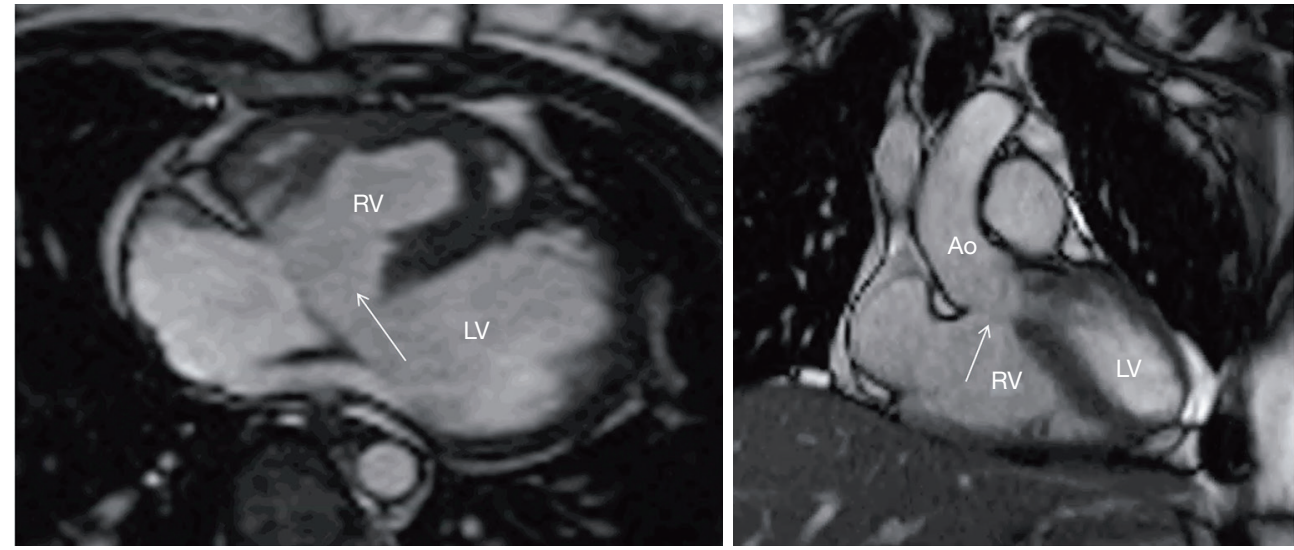

Figure 3 A 42-year-old patient with a large uncorrected ventricular septal defect (arrow) and Eisenmenger syndrome. LV, left ventricular; $\mathrm{RV}$, right ventricular; Ao, aorta.
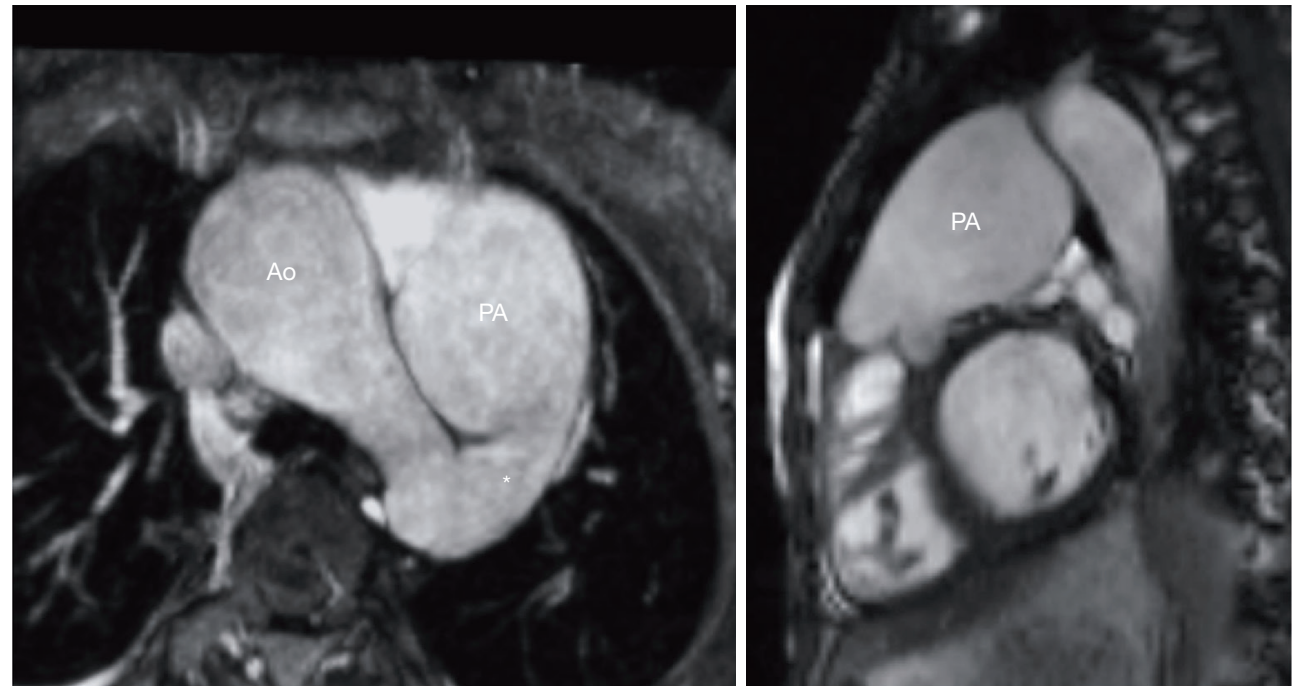

Figure 4 A 20-year-old female PH patient caused by a large patent arterial duct $\left(^{*}\right)$. Ao, aorta; PA, pulmonary artery; PH, pulmonary hypertension.

$\mathrm{PH}$ and to monitor chronic changes of pulmonary vascular resistance (PVR) under therapy. Several experimental studies in animals and clinical studies in patients found correlations between PAP and PVR with various measures of pulmonary stiffness such as pulsatility, compliance, capacitance and distensibility (22). These parameters can be quantified using a cross-sectional cine image through the pulmonary trunk and/or the branch pulmonary arteries and are combined with invasively assessed pulmonary artery pulse pressure $(22,23,54,55)$. Analysis of pulmonary artery stiffness by measuring blood flow velocity in the pulmonary arteries with two-dimensional phase contrast flow sequences has been validated in children with PH. Importantly, flow sequences with a high temporal resolution are required to allow assessment of flow and vessel area that enable to calculate measures of arterial stiffness such as pulse wave velocity (PWV) (24) or wave intensity using post-processing workflows $(25,56)$. In 40 children with $\mathrm{PAH}$, Schäfer and colleagues demonstrated that different measures of wave intensity correlated with mean PAP, RV size and function (25). The same group also demonstrated that pulmonary artery stiffness is associated with functional worsening of disease severity and might therefore be helpful for determining prognosis and monitoring disease 
progression in children with $\mathrm{PAH}(24,25)$.

As an alternative to quantify RV afterload, Pandya and colleagues verified a technique to analyze the position of the interventricular septum (septal curvature) (57-59) in pediatric $\mathrm{PH}$ patients using real-time CMR cine imaging. This group compared septal curvature metrics with simultaneously assessed invasive PAP at baseline and during vasodilator testing with NO (21). They found a significant correlation between mean PAP the interventricular septal curvature that also accurately tracked changes of PAP during pulmonary vasodilation.

\section{Pulmonary arterial wall shear stress (WSS)}

Pulmonary vascular endothelial dysfunction is an important mechanism involved in the pathophysiology of $\mathrm{PH}$ (60). Reduced WSS impairs vasorelaxation properties in the pulmonary vasculature and acts as a major contributor to adverse remodeling and $\mathrm{PH}$. By using CMR phase contrast flow, quantification of WSS along the main pulmonary artery (MPA) lumen has been performed and demonstrated significant lower values compared to healthy controls (see Figure 5) (24). Lower WSS was also related to increased proximal pulmonary artery stiffness and reduced RV myocardial function (26). Whether assessment of WSS serves as an early indicator of clinical decline or allows monitoring of the response to $\mathrm{PH}$ targeted therapy remains unknown.

\section{$R V$ myocardial deformation and synchrony}

$\mathrm{RV}$ dysfunction is associated with significant morbidity and mortality in patients with $\mathrm{PH}$ and represents the leading cause for death in the adult $\mathrm{PH}$ population $(36,61)$. As seen with LV dysfunction, myocardial deformation parameters seem potentially more sensitive to detect an early decline in RV function before global pump function (i.e., EF) decreases. Several echocardiographic studies in adults and children with $\mathrm{PH}$ found RV myocardial strain to correlate with disease severity, global hemodynamics and outcome (62). CMR based techniques to characterize myocardial contraction include (time consuming) tagging techniques and post-processing software tools such feature tracking/tissue tracking techniques that allow rapid strain quantification from standard cine images. Data regarding CMR based RV strain analysis in $\mathrm{PH}$ patients is limited to a study in adult patients by de Siqueira et al. that demonstrated the feasibility to quantify RV strain in this population, correlated with disease severity and was an independent predictor of poor outcome (see Figure 6) (30). In children with $\mathrm{PH}$, Schäfer and colleagues analyzed RV mechanics including strain and synchrony by CMR and found important associations with the presence of electrical dyssynchrony (assessed by QRS z-scores) and impaired RV function (31). Finally, characterization of right atrial deformation, either by echocardiography or CMR, seems to add important hemodynamic and prognostic information (63-65).

\section{$R V$-pulmonary arterial coupling}

The framework of ventricular-arterial coupling (VAC) has emerged as an important parameter in patients with $\mathrm{PAH}$ that carries prognostic significance in both the adult and pediatric $\mathrm{PH}$ population (66-68). VAC is estimated as the ratio of the two measures pulmonary arterial elastance Ea and ventricular elastance Ees. Pulmonary arterial elastance $\mathrm{Ea}$ is defined as the ratio of ventricular end-systolic pressure divided by stroke volume and incorporates all elements of total ventricular afterload including peripheral resistance, arterial compliance and characteristic impedance. Ventricular end-systolic elastance Ees describes a loadindependent parameter of myocardial contractility and is defined as the ratio of ventricular end-systolic pressure and end-systolic volume. It has been demonstrated that normal $\mathrm{RV}$ functional adaptation to afterload is associated with maintenance of an $\mathrm{Ea} / \mathrm{Ees}$ ratio of about 0.5 to 1.0, allowing for flow output at a low amount of oxygen consumption. Although usually determined by invasive assessment of ventricular pressure-volume loops under various loading conditions, Sanz and colleagues demonstrated that VAC can be determined non-invasively using CMR by the measure end-systolic volume divided by stroke volume (27). Although the proposed assumption seems error-prone (69), Truong and colleagues were able to confirm its usefulness in a smaller cohort of pediatric patients with miscellaneous types of PH (28). They also noted that VA uncoupling was already present in non-responders to NO suggesting that this concept is particularly valuable to serially follow $\mathrm{PH}$ patients over time (70). In an extension of their previous study and including data from a second pediatric $\mathrm{PH}$ centre, this group demonstrated that both invasively and noninvasively assessed VAC correlated with functional and hemodynamic measures of disease severity (29). 

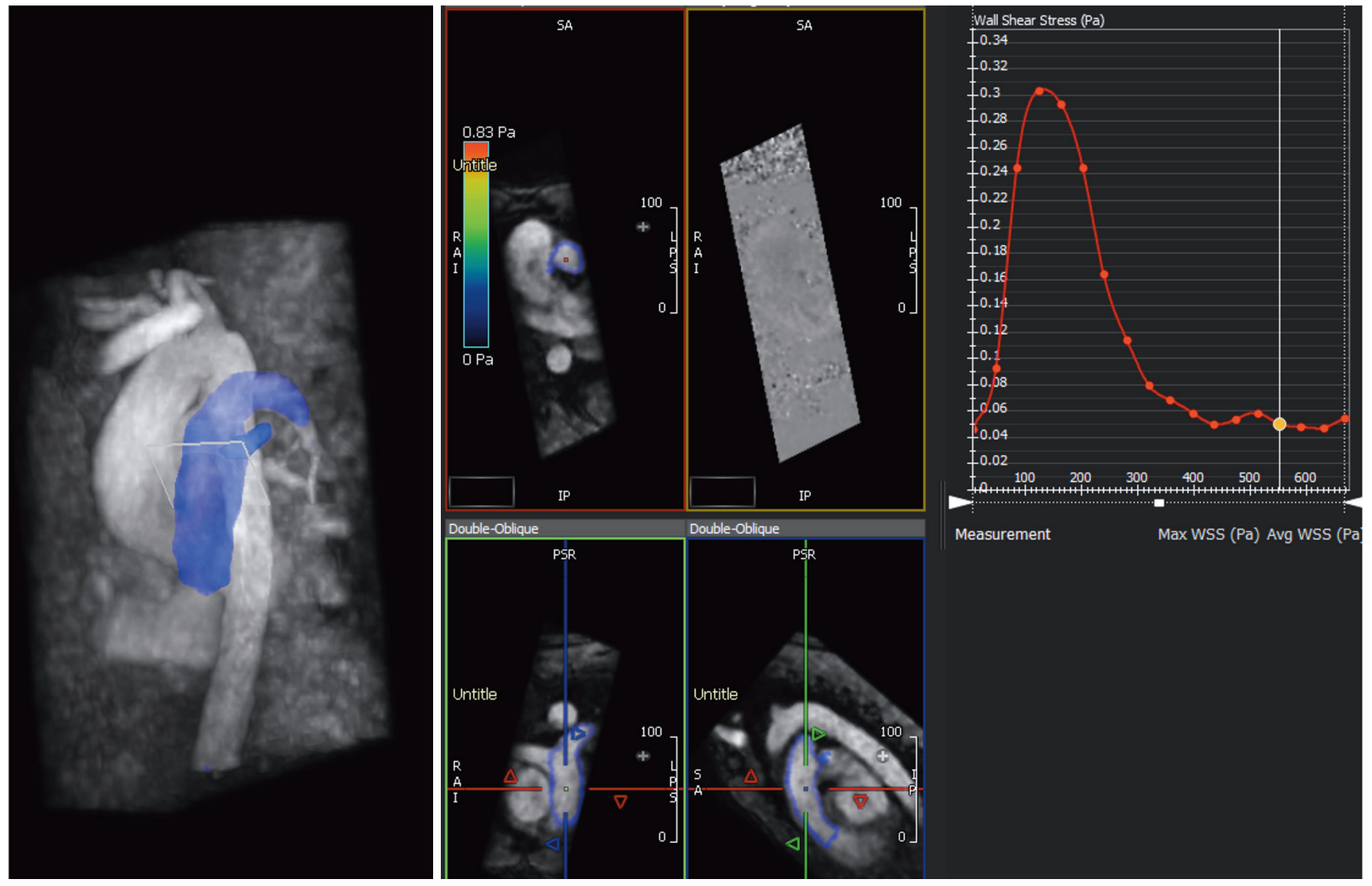

Figure 5 Exemplary representation of wall shear stress (WSS) assessment in the main pulmonary artery of a healthy volunteer using CMR 4D flow technique. 3D velocity acquisition with resulting angiogram (left) and manual segmentation of the pulmonary artery trunk (blue surface) are displayed followed by automatic calculation of peak and average WSS (red curve) by a commercially available software tool. CMR, cardiovascular magnetic resonance.

\section{Ventricular and vascular right-left heart interactions}

Although LV and RV function are usually considered separately, a considerable myocardial cross-talk between the two ventricles exists through a shared septum and pericardium $(71,72)$. In the presence of increased $R V$ pressure due to a rise in PA pressures, abnormalities in systolic and diastolic LV function evolve (73). Attempts to identify underlying pathophysiological mechanisms and assessing the clinical relevance of $L V$ dysfunction in pediatric patients with $\mathrm{PH}$ have been made. As a result of an altered position of the interventricular septum, impaired LV diastolic filling $(74,75)$ and reduced $L V$ torsion have been reported in $\mathrm{PH}$ patients (76). Progressive electrical dyssynchrony occurring with RV dilatation and dysfunction further contributes to systolic LV dysfunction and a discoordinate contraction pattern that, in turn, is of prognostic relevance $(31,32)$. Accompanied by adverse interactions on the ventricular level, increased stiffness of the ascending aorta seems to be present and is directly related to MPA distension. As a consequence of increased afterload, VA uncoupling and LV dysfunction may occur that compromise systemic arterial hemodynamics (77).

\section{Combined CMR with cardiac catheterization}

If $\mathrm{PH}$ is suspected, right-heart catheterization with vasoreactivity testing is considered as the gold standard for diagnosis and also provides information to guide medical therapy and to assess prognosis. New options for PAP evaluation by CMR-guided cardiac catheterization make it feasible to perform the procedure without ionizing radiation (see example in Figure 7) $(33,78,79)$. This represents a very 

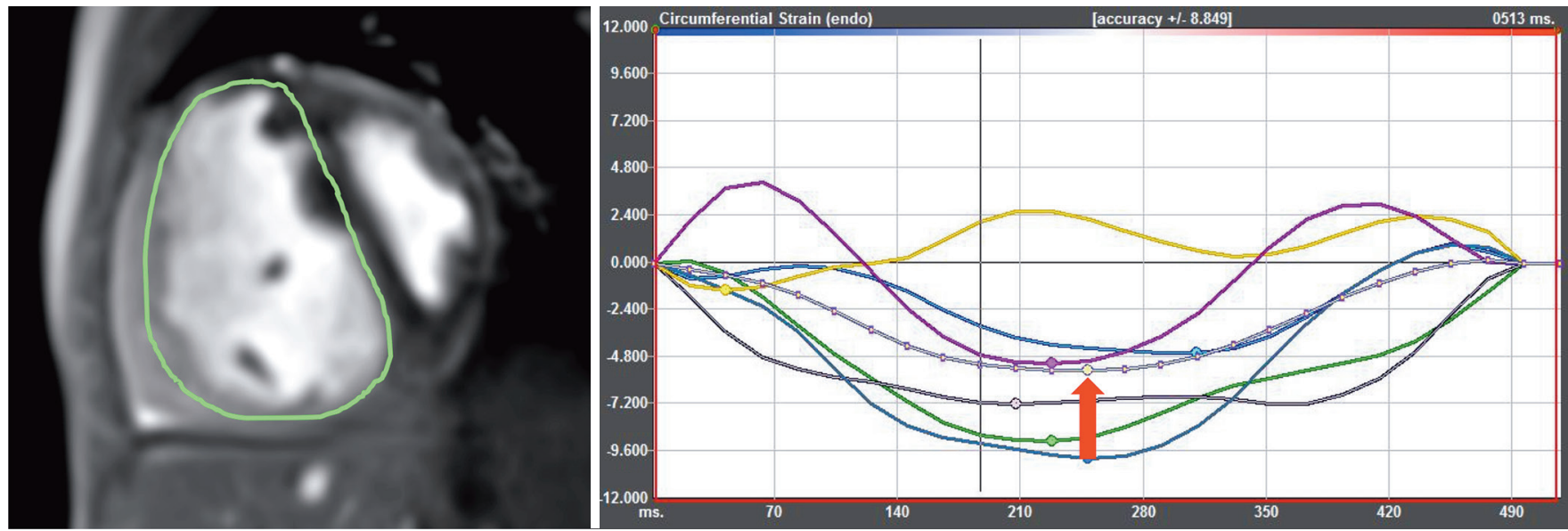

Figure 6 Analysis of right ventricular deformation from a standard short axis cine image using CMR feature tracking technique (left). After manual placement of 8-10 points along the endocardial border (green line), the software automatically tracks its movement over the cardiac cycle and allows quantification of parameters such as systolic and diastolic myocardial strain (right image: peak global circumferential strain, red arrow) as well as intra- and interventricular synchrony. CMR, cardiovascular magnetic resonance.

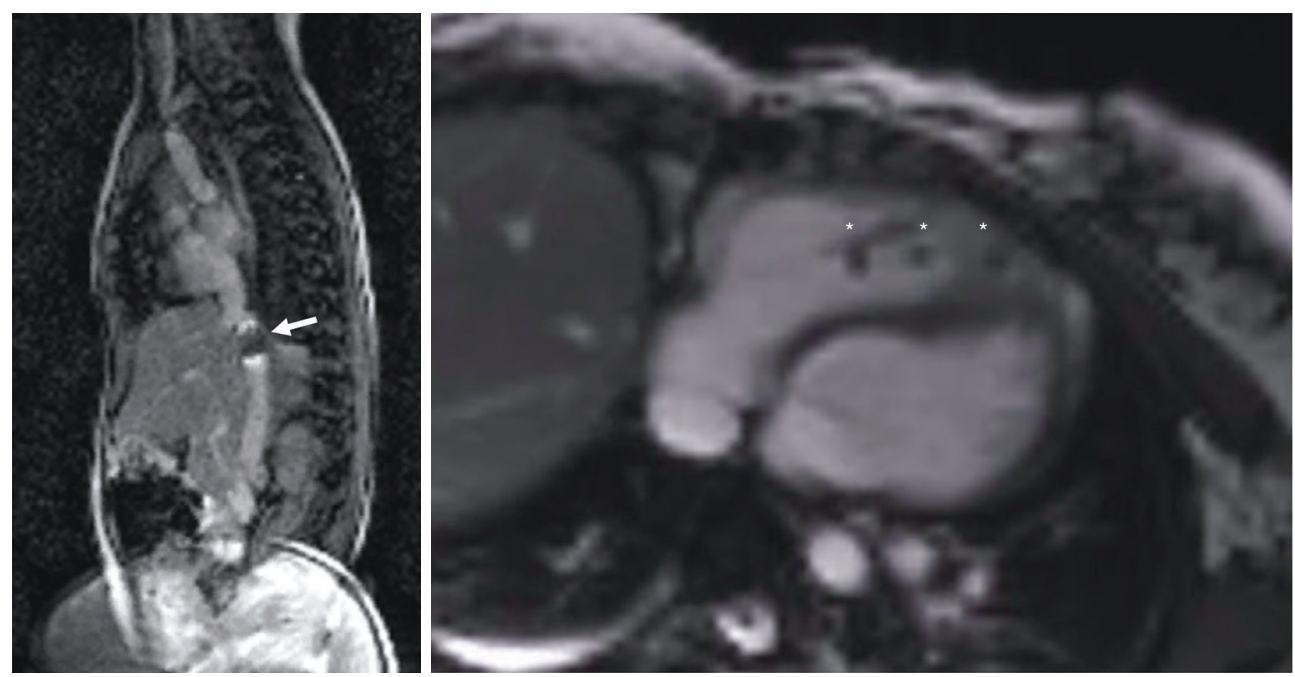

Figure 7 Combined CMR and cardiac catheterization study for assessment of invasive right ventricular pressure. Left image: balloon inflated with $\mathrm{CO}_{2}$ in the inferior caval vein (white arrow). Right image: a CMR compatible guidewire placed in the right ventricle (* , markers on the guidewire).

attractive option for diagnosis of $\mathrm{PH}$ especially in children and might become more widely available in the near future even in conventional CMR environments. Recently, Knight et al. showed in 50 adult patients, the majority presenting with $\mathrm{PH}$, that the examination is feasible with short examination times (34). Additionally, simultaneous assessment of cardiac output by phase contrast flow allows a more reliable calculation of PVR compared to conventional techniques (thermodilution or oximetry). In a study by Pushparajah and colleagues (14), both CMR and invasive fluoroscopic guided cardiac catheterization were performed to calculate PVR in 108 patients with biventricular circulation and left-to-right shunt lesions that were evaluated for suitability for surgical correction. The authors were able to define a cut-off in baseline Qp/Qs of $\leq 2.75$ predicted a PVR $\geq 6$ WU.m ${ }^{2}$ with $100 \%$ sensitivity and 
$48 \%$ specificity (14). Accordingly, CMR augmented cardiac catheterization allows accurate stratification for intervention in patients with biventricular CHD. Finally, creation of pressure-volume loops from simultaneous assessment of RV pressure and volume by CMR cine images may provide a more precise calculation of ventricular contractility Ees, load-independent parameters of ventricular stiffness and $\operatorname{VAC}(79-81)$.

\section{Innovative CMR imaging techniques and potential future applications}

The role of 4-dimensional (4D) CMR flow imaging has been evaluated in patients with $\mathrm{PH}$. Visualization of flow pattern with vortex formation (82), WSS (83), PWV, kinetic energy loss (84) and intraventricular flow (85) were derived from a 4D data set and may add in the non-invasive diagnosis and hemodynamic assessment of $\mathrm{PH}$ patients. By comparing pulmonary artery flow hemodynamics in children and adults with PAH matched for similar PVR, Schäfer and colleagues demonstrated that the variability in flow hemodynamic abnormalities was higher in children whereas reduced WSS contributed to adverse pulmonary vascular hemodynamics in both groups (86). Furthermore, this group demonstrated the usefulness of $4 \mathrm{D}$ flow in a patient after complex palliation with a Potts shunt by illustrating a primary right-to-left shunt through the shunt (87). At last, based on CMR data, developments in the area of artificial intelligence with deep learning algorithms (88) and computational modeling (89) may improve risk stratification in $\mathrm{PH}$ patients.

\section{Acknowledgments}

Funding: None.

\section{Footnote}

Provenance and Peer Review: This article was commissioned by the Guest Editors (Christian Apitz and Astrid Lammers) for the series "Pediatric Pulmonary Hypertension" published in Cardiovascular Diagnosis and Therapy. The article has undergone external peer review.

Conflicts of Interest: Both authors have completed the ICMJE uniform disclosure forms (available at http://dx.doi. org/10.21037/cdt-20-270). The series "Pediatric Pulmonary Hypertension" was commissioned by the editorial office without any funding or sponsorship. The authors have no other conflicts of interest to declare.

Ethical Statement: The authors are accountable for all aspects of the work in ensuring that questions related to the accuracy or integrity of any part of the work are appropriately investigated and resolved.

Open Access Statement: This is an Open Access article distributed in accordance with the Creative Commons Attribution-NonCommercial-NoDerivs 4.0 International License (CC BY-NC-ND 4.0), which permits the noncommercial replication and distribution of the article with the strict proviso that no changes or edits are made and the original work is properly cited (including links to both the formal publication through the relevant DOI and the license). See: https://creativecommons.org/licenses/by-nc-nd/4.0/.

\section{References}

1. Simonneau G, Gatzoulis MA, Adatia I, et al. Updated clinical classification of pulmonary hypertension. J Am Coll Cardiol 2013;62:D34-41.

2. Simonneau G, Montani D, Celermajer DS, et al. Haemodynamic definitions and updated clinical classification of pulmonary hypertension. Eur Respir J 2019;53:1801913.

3. Fratz S, Chung T, Greil GF, et al. Guidelines and protocols for cardiovascular magnetic resonance in children and adults with congenital heart disease: SCMR expert consensus group on congenital heart disease. J Cardiovasc Magn Reson 2013;15:51.

4. Koestenberger M, Apitz C, Abdul-Khaliq H, et al. Transthoracic echocardiography for the evaluation of children and adolescents with suspected or confirmed pulmonary hypertension. Expert consensus statement on the diagnosis and treatment of paediatric pulmonary hypertension. The European Paediatric Pulmonary Vascular Disease Network, endorsed by ISHLT and D6PK. Heart 2016;102 Suppl 2:ii14-22.

5. Apitz C, Hansmann G, Schranz D. Hemodynamic assessment and acute pulmonary vasoreactivity testing in the evaluation of children with pulmonary vascular disease. Expert consensus statement on the diagnosis and treatment of paediatric pulmonary hypertension. The European Paediatric Pulmonary Vascular Disease Network, endorsed by ISHLT and DGPK. Heart 2016;102 Suppl 2:ii23-9.

6. Valsangiacomo Buechel ER, Grosse-Wortmann L, Fratz 
$\mathrm{S}$, et al. Indications for cardiovascular magnetic resonance in children with congenital and acquired heart disease: an expert consensus paper of the Imaging Working Group of the AEPC and the Cardiovascular Magnetic Resonance Section of the EACVI. Eur Heart J Cardiovasc Imaging 2015;16:281-97.

7. Ascha M, Renapurkar RD, Tonelli AR. A review of imaging modalities in pulmonary hypertension. Ann Thorac Med 2017;12:61-73.

8. Blalock S, Chan F, Rosenthal D, et al. Magnetic resonance imaging of the right ventricle in pediatric pulmonary arterial hypertension. Pulm Circ 2013;3:350-5.

9. Moledina S, Pandya B, Bartsota M, et al. Prognostic significance of cardiac magnetic resonance imaging in children with pulmonary hypertension. Circ Cardiovasc Imaging 2013;6:407-14.

10. Swift AJ, Rajaram S, Condliffe R, et al. Diagnostic accuracy of cardiovascular magnetic resonance imaging of right ventricular morphology and function in the assessment of suspected pulmonary hypertension results from the ASPIRE registry. J Cardiovasc Magn Reson 2012;14:40.

11. van de Veerdonk MC, Kind T, Marcus JT, et al. Progressive right ventricular dysfunction in patients with pulmonary arterial hypertension responding to therapy. $\mathrm{J}$ Am Coll Cardiol 2011;58:2511-9.

12. Latus H, Kuehne T, Beerbaum P, et al. Cardiac MR and CT imaging in children with suspected or confirmed pulmonary hypertension/pulmonary hypertensive vascular disease. Expert consensus statement on the diagnosis and treatment of paediatric pulmonary hypertension. The European Paediatric Pulmonary Vascular Disease Network, endorsed by ISHLT and DGPK. Heart 2016;102 Suppl 2:ii30-5.

13. Meng H, Grosse-Wortmann L. Gadolinium in pediatric cardiovascular magnetic resonance: what we know and how we practice. J Cardiovasc Magn Reson 2012;14:56.

14. Pushparajah K, Tzifa A, Bell A, et al. Cardiovascular magnetic resonance catheterization derived pulmonary vascular resistance and medium-term outcomes in congenital heart disease. J Cardiovasc Magn Reson 2015;17:28.

15. Caro-Domínguez P, Compton G, Humpl T, et al. Pulmonary arterial hypertension in children: diagnosis using ratio of main pulmonary artery to ascending aorta diameter as determined by multi-detector computed tomography. Pediatr Radiol 2016;46:1378-83.

16. Rajaram S, Swift AJ, Telfer A, et al. 3D contrast-enhanced lung perfusion MRI is an effective screening tool for chronic thromboembolic pulmonary hypertension: results from the ASPIRE Registry. Thorax 2013;68:677-8.

17. Ohno Y, Koyama H, Yoshikawa T, et al. Contrastenhanced multidetector-row computed tomography vs. Time-resolved magnetic resonance angiography vs. contrast-enhanced perfusion MRI: assessment of treatment response by patients with inoperable chronic thromboembolic pulmonary hypertension. J Magn Reson Imaging 2012;36:612-23.

18. Swift AJ, Rajaram S, Capener D, et al. LGE Patterns in Pulmonary Hypertension Do Not Impact Overall Mortality. JACC Cardiovasc Imaging 2014;7:1209-17.

19. Spruijt OA, Vissers L, Bogaard HJ, et al. Increased native $\mathrm{T} 1$-values at the interventricular insertion regions in precapillary pulmonary hypertension. Int J Cardiovasc Imaging 2016;32:451-9.

20. Saunders LC, Johns CS, Stewart NJ, et al. Diagnostic and prognostic significance of cardiovascular magnetic resonance native myocardial $\mathrm{T} 1$ mapping in patients with pulmonary hypertension. J Cardiovasc Magn Reson 2018;20:78.

21. Pandya B, Quail MA, Steeden JA, et al. Real-time magnetic resonance assessment of septal curvature accurately tracks acute hemodynamic changes in pediatric pulmonary hypertension. Circ Cardiovasc Imaging 2014;7:706-13.

22. Sanz J, Kariisa M, Dellegrottaglie S, et al. Evaluation of pulmonary artery stiffness in pulmonary hypertension with cardiac magnetic resonance. JACC Cardiovasc Imaging 2009;2:286-95.

23. Swift AJ, Rajaram S, Hurdman J, et al. Noninvasive estimation of PA pressure, flow, and resistance with CMR imaging: derivation and prospective validation study from the ASPIRE registry. JACC Cardiovasc Imaging 2013;6:1036-47.

24. Friesen RM, Schäfer M, Ivy DD, et al. Proximal pulmonary vascular stiffness as a prognostic factor in children with pulmonary arterial hypertension. Eur Heart J Cardiovasc Imaging 2019;20:209-17.

25. Schäfer M, Wilson N, Ivy DD, et al. Noninvasive wave intensity analysis predicts functional worsening in children with pulmonary arterial hypertension. Am J Physiol Heart Circ Physiol 2018;315:H968-77.

26. Schäfer M, Ivy DD, Barker AJ, et al. Characterization of CMR-derived haemodynamic data in children with pulmonary arterial hypertension. Eur Heart J Cardiovasc Imaging 2017;18:424-31.

27. Sanz J, Garcia-Alvarez A, Fernandez-Friera L, et al. Right 
ventriculo-arterial coupling in pulmonary hypertension: a magnetic resonance study. Heart 2012;98:238-43.

28. Truong U, Patel S, Kheyfets V, et al. Non-invasive determination by cardiovascular magnetic resonance of right ventricular-vascular coupling in children and adolescents with pulmonary hypertension. J Cardiovasc Magn Reson 2015;17:81.

29. Breeman KTN, Dufva M, Ploegstra MJ, et al. Right ventricular-vascular coupling ratio in pediatric pulmonary arterial hypertension: A comparison between cardiac magnetic resonance and right heart catheterization measurements. Int J Cardiol 2019;293:211-7.

30. de Siqueira ME, Pozo E, Fernandes VR, et al. Characterization and clinical significance of right ventricular mechanics in pulmonary hypertension evaluated with cardiovascular magnetic resonance feature tracking. J Cardiovasc Magn Reson 2016;18:39.

31. Schäfer M, Collins KK, Browne LP, et al. Effect of electrical dyssynchrony on left and right ventricular mechanics in children with pulmonary arterial hypertension. J Heart Lung Transplant 2018;37:870-8.

32. Frank BS, Schäfer M, Douwes JM, et al. Novel measures of left ventricular electromechanical discoordination predict clinical outcomes in children with pulmonary arterial hypertension. Am J Physiol Heart Circ Physiol 2020;318:H401-12.

33. Rogers T, Ratnayaka K, Khan JM, et al. CMR fluoroscopy right heart catheterization for cardiac output and pulmonary vascular resistance: results in 102 patients. J Cardiovasc Magn Reson 2017;19:54.

34. Knight DS, Kotecha T, Martinez-Naharro A, et al. Cardiovascular magnetic resonance-guided right heart catheterization in a conventional CMR environment predictors of procedure success and duration in pulmonary artery hypertension. J Cardiovasc Magn Reson 2019;21:57.

35. van Wolferen SA, Marcus JT, Boonstra A, et al. Prognostic value of right ventricular mass, volume, and function in idiopathic pulmonary arterial hypertension. Eur Heart J 2007;28:1250-7.

36. Tonelli AR, Arelli V, Minai OA, et al. Causes and circumstances of death in pulmonary arterial hypertension. Am J Respir Crit Care Med 2013;188:365-9.

37. Peacock AJ, Crawley S, McLure L, et al. Changes in right ventricular function measured by cardiac magnetic resonance imaging in patients receiving pulmonary arterial hypertension-targeted therapy: the EURO-MR study. Circ Cardiovasc Imaging 2014;7:107-14.

38. Jensen AS, Broberg CS, Rydman R, et al. Impaired
Right, Left, or Biventricular Function and Resting Oxygen Saturation Are Associated With Mortality in Eisenmenger Syndrome: A Clinical and Cardiovascular Magnetic Resonance Study. Circ Cardiovasc Imaging 2015;8:e003596.

39. Bell A, Beerbaum P, Greil G, et al. Noninvasive assessment of pulmonary artery flow and resistance by cardiac magnetic resonance in congenital heart diseases with unrestricted left-to-right shunt. JACC Cardiovasc Imaging 2009;2:1285-91.

40. Beerbaum P, Korperich H, Barth P, et al. Noninvasive quantification of left-to-right shunt in pediatric patients: phase-contrast cine magnetic resonance imaging compared with invasive oximetry. Circulation 2001;103:2476-82.

41. Shariat M, Grosse-Wortmann L, Windram J, et al. Pulmonary vein flow pattern in children with bidirectional cavopulmonary connection or Fontan circuit. Pediatr Radiol 2012;42:211-4.

42. Compton GL, Florence J, MacDonald C, et al. Main Pulmonary Artery-to-Ascending Aorta Diameter Ratio in Healthy Children on MDCT. AJR Am J Roentgenol 2015;205:1322-5.

43. Frank H, Globits S, Glogar D, et al. Detection and quantification of pulmonary artery hypertension with $M R$ imaging: results in 23 patients. AJR Am J Roentgenol 1993;161:27-31.

44. McLure LE, Peacock AJ. Cardiac magnetic resonance imaging for the assessment of the heart and pulmonary circulation in pulmonary hypertension. Eur Respir J 2009;33:1454-66.

45. Alunni JP, Degano B, Arnaud C, et al. Cardiac MRI in pulmonary artery hypertension: correlations between morphological and functional parameters and invasive measurements. Eur Radiol 2010;20:1149-59.

46. Freed BH, Gomberg-Maitland M, Chandra S, et al. Late gadolinium enhancement cardiovascular magnetic resonance predicts clinical worsening in patients with pulmonary hypertension. J Cardiovasc Magn Reson 2012;14:11.

47. Sato T, Tsujino I, Ohira H, et al. Paradoxical interventricular septal motion as a major determinant of late gadolinium enhancement in ventricular insertion points in pulmonary hypertension. PLoS One 2013;8:e66724.

48. Blyth KG, Groenning BA, Martin TN, et al. Contrast enhanced-cardiovascular magnetic resonance imaging in patients with pulmonary hypertension. Eur Heart J 2005;26:1993-9. 
49. McCann GP, Beek AM, Vonk-Noordegraaf A, et al. Delayed contrast-enhanced magnetic resonance imaging in pulmonary arterial hypertension. Circulation 2005;112:e268.

50. Broberg CS, Prasad SK, Carr C, et al. Myocardial fibrosis in Eisenmenger syndrome: a descriptive cohort study exploring associations of late gadolinium enhancement with clinical status and survival. J Cardiovasc Magn Reson 2014;16:32.

51. Patel RB, Li E, Benefield BC, et al. Diffuse right ventricular fibrosis in heart failure with preserved ejection fraction and pulmonary hypertension. ESC Heart Fail 2020;7:253-63.

52. Chen YY, Yun H, Jin H, et al. Association of native T1 times with biventricular function and hemodynamics in precapillary pulmonary hypertension. Int J Cardiovasc Imaging 2017;33:1179-89.

53. Reiter U, Reiter G, Kovacs G, et al. Native myocardial T1 mapping in pulmonary hypertension: correlations with cardiac function and hemodynamics. Eur Radiol 2017;27:157-66.

54. García-Álvarez A, Fernandez-Friera L, Garcia-Ruiz $\mathrm{JM}$, et al. Noninvasive monitoring of serial changes in pulmonary vascular resistance and acute vasodilator testing using cardiac magnetic resonance. J Am Coll Cardiol 2013;62:1621-31.

55. García-Alvarez A, Fernandez-Friera L, Mirelis JG, et al. Non-invasive estimation of pulmonary vascular resistance with cardiac magnetic resonance. Eur Heart J 2011;32:2438-45.

56. Quail MA, Knight DS, Steeden JA, et al. Noninvasive pulmonary artery wave intensity analysis in pulmonary hypertension. Am J Physiol Heart Circ Physiol 2015;308:H1603-11.

57. Dellegrottaglie S, Sanz J, Poon M, et al. Pulmonary hypertension: accuracy of detection with left ventricular septal-to-free wall curvature ratio measured at cardiac MR. Radiology 2007;243:63-9.

58. Roeleveld RJ, Marcus JT, Faes TJ, et al. Interventricular septal configuration at $\mathrm{mr}$ imaging and pulmonary arterial pressure in pulmonary hypertension. Radiology 2005;234:710-7.

59. Brinker JA, Weiss JL, Lappe DL, et al. Leftward septal displacement during right ventricular loading in man. Circulation 1980;61:626-33.

60. Apitz C, Zimmermann R, Kreuder J, et al. Assessment of pulmonary endothelial function during invasive testing in children and adolescents with idiopathic pulmonary arterial hypertension. J Am Coll Cardiol 2012;60:157-64.

61. Ploegstra MJ, Roofthooft MT, Douwes JM, et al. Echocardiography in pediatric pulmonary arterial hypertension: early study on assessing disease severity and predicting outcome. Circ Cardiovasc Imaging 2014;8:e000878.

62. Jone PN, Schäfer M, Pan Z, et al. 3D echocardiographic evaluation of right ventricular function and strain: a prognostic study in paediatric pulmonary hypertension. Eur Heart J Cardiovasc Imaging 2018;19:1026-33.

63. Jone PN, Schäfer M, Li L, et al. Right Atrial Deformation in Predicting Outcomes in Pediatric Pulmonary Hypertension. Circ Cardiovasc Imaging 2017;10:e006250.

64. Richter MJ, Fortuni F, Wiegand MA, et al. Association of right atrial conduit phase with right ventricular lusitropic function in pulmonary hypertension. Int $\mathrm{J}$ Cardiovasc Imaging 2020;36:633-42.

65. Tello K, Dalmer A, Vanderpool R, et al. Right ventricular function correlates of right atrial strain in pulmonary hypertension: a combined cardiac magnetic resonance and conductance catheter study. Am J Physiol Heart Circ Physiol 2020;318:H156-64.

66. Vanderpool RR, Pinsky MR, Naeije R, et al. RVpulmonary arterial coupling predicts outcome in patients referred for pulmonary hypertension. Heart 2015;101:37-43.

67. Jone PN, Schäfer M, Pan Z, et al. Right VentricularArterial Coupling Ratio Derived From 3-Dimensional Echocardiography Predicts Outcomes in Pediatric Pulmonary Hypertension. Circ Cardiovasc Imaging 2019;12:e08176.

68. Richter MJ, Peters D, Ghofrani HA, et al. Evaluation and Prognostic Relevance of Right Ventricular-Arterial Coupling in Pulmonary Hypertension. Am J Respir Crit Care Med 2020;201:116-9.

69. Tello K, Richter MJ, Axmann J, et al. More on SingleBeat Estimation of Right Ventriculoarterial Coupling in Pulmonary Arterial Hypertension. Am J Respir Crit Care Med 2018;198:816-8.

70. Aggarwal M, Grady RM, Choudhry S, et al. Potts Shunt Improves Right Ventricular Function and Coupling With Pulmonary Circulation in Children With Suprasystemic Pulmonary Arterial Hypertension. Circ Cardiovasc Imaging 2018;11:e007964.

71. Burns KM, Byrne BJ, Gelb BD, et al. New mechanistic and therapeutic targets for pediatric heart failure: report from a National Heart, Lung, and Blood Institute working group. Circulation 2014;130:79-86. 
72. Damiano RJ Jr, La Follette P Jr, Cox JL, et al. Significant left ventricular contribution to right ventricular systolic function. Am J Physiol 1991;261:H1514-24.

73. Burkett DA, Slorach C, Patel SS, et al. Left Ventricular Myocardial Function in Children With Pulmonary Hypertension: Relation to Right Ventricular Performance and Hemodynamics. Circ Cardiovasc Imaging 2015;8:e003260.

74. Knight DS, Steeden JA, Moledina S, et al. Left ventricular diastolic dysfunction in pulmonary hypertension predicts functional capacity and clinical worsening: a tissue phase mapping study. J Cardiovasc Magn Reson 2015;17:116.

75. Burkett DA, Slorach C, Patel SS, et al. Impact of Pulmonary Hemodynamics and Ventricular Interdependence on Left Ventricular Diastolic Function in Children With Pulmonary Hypertension. Circ Cardiovasc Imaging 2016;9:e004612.

76. Dufva MJ, Truong U, Tiwari P, et al. Left ventricular torsion rate and the relation to right ventricular function in pediatric pulmonary arterial hypertension. Pulm Circ 2018;8:2045894018791352.

77. Schäfer M, Ivy DD, Abman SH, et al. Apparent Aortic Stiffness in Children With Pulmonary Arterial Hypertension: Existence of Vascular Interdependency? Circ Cardiovasc Imaging 2017;10:e005817.

78. Ratnayaka K, Kanter JP, Faranesh AZ, et al. Radiationfree CMR diagnostic heart catheterization in children. J Cardiovasc Magn Reson 2017;19:65.

79. Kuehne T, Yilmaz S, Schulze-Neick I, et al. Magnetic resonance imaging guided catheterisation for assessment of pulmonary vascular resistance: in vivo validation and clinical application in patients with pulmonary hypertension. Heart 2005;91:1064-9.

80. Kuehne T, Yilmaz S, Steendijk P, et al. Magnetic resonance imaging analysis of right ventricular pressurevolume loops: in vivo validation and clinical application in patients with pulmonary hypertension. Circulation 2004;110:2010-6.

81. Rain S, Handoko ML, Trip P, et al. Right ventricular

Cite this article as: Latus $\mathrm{H}$, Meierhofer C. Role of cardiovascular magnetic resonance in pediatric pulmonary hypertension-novel concepts and imaging biomarkers. Cardiovasc Diagn Ther 2021;11(4):1057-1069. doi: 10.21037/ cdt-20-270 diastolic impairment in patients with pulmonary arterial hypertension. Circulation 2013;128:2016-25, 1-10.

82. Reiter G, Reiter U, Kovacs G, et al. Magnetic resonancederived 3-dimensional blood flow patterns in the main pulmonary artery as a marker of pulmonary hypertension and a measure of elevated mean pulmonary arterial pressure. Circ Cardiovasc Imaging 2008;1:23-30.

83. Barker AJ, Roldan-Alzate A, Entezari P, et al. Fourdimensional flow assessment of pulmonary artery flow and wall shear stress in adult pulmonary arterial hypertension: results from two institutions. Magn Reson Med 2015;73:1904-13.

84. Han QJ, Witschey WR, Fang-Yen CM, et al. Altered Right Ventricular Kinetic Energy Work Density and Viscous Energy Dissipation in Patients with Pulmonary Arterial Hypertension: A Pilot Study Using 4D Flow MRI. PLoS One 2015;10:e138365.

85. Kheyfets VO, Schäfer M, Podgorski CA, et al. 4D magnetic resonance flow imaging for estimating pulmonary vascular resistance in pulmonary hypertension. J Magn Reson Imaging 2016;44:914-22.

86. Schäfer M, Ivy DD, Abman SH, et al. Differences in pulmonary arterial flow hemodynamics between children and adults with pulmonary arterial hypertension as assessed by 4D-flow CMR studies. Am J Physiol Heart Circ Physiol 2019;316:H1091-104.

87. Schäfer M, Frank BS, Ivy DD, et al. Close look at the Potts shunt flow hemodynamics in a patient with severe pulmonary hypertension: 4D-flow MRI evaluation. J Magn Reson Imaging 2019;49:1800-2.

88. Dawes TJW, de Marvao A, Shi W, et al. Machine Learning of Three-dimensional Right Ventricular Motion Enables Outcome Prediction in Pulmonary Hypertension: A Cardiac MR Imaging Study. Radiology 2017;283:381-90.

89. Attard MI, Dawes TJW, de Marvao A, et al. Metabolic pathways associated with right ventricular adaptation to pulmonary hypertension: 3D analysis of cardiac magnetic resonance imaging. Eur Heart J Cardiovasc Imaging 2019;20:668-76. 